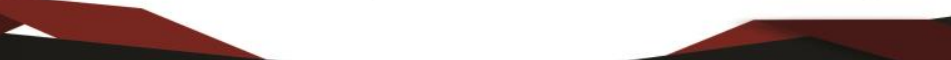

Relato de Caso

\title{
Atuação da Controladoria Geral no Planejamento Público Municipal: Análise da Controladoria Geral de Curaçá/BA
}

Silvana Rodrigues Paixão ${ }^{l}$

\begin{abstract}
Resumo: O presente estudo teve como objetivo analisar a atuação da Controladoria Geral no Planejamento Público Municipal, tendo como estudo central, a cidade de Curaçá. Para subsidiar o estudo, foi utilizada a pesquisa exploratória, bibliográfica, documental e de campo. Coletando os dados através da aplicação de questionário, direcionado a servidores que ocuparam o cargo de Controlador Geral do Município, entre o período de 2009 a 2018. Trazendo a experiência daqueles que ocuparam, nesse período. Podendo concluir, acerca da atuação da Controladoria no processo de Planejamento dos instrumentos que dão subsídio a gestão Municipal, não obedece aos preceitos legais, tendo em vista que a Controladoria não participa de forma efetiva do Planejamento, carecendo que a partir dessa pesquisa, as gestões passem a ter outro olhar para a importante tarefa que a Controladoria Geral exerce, principalmente na segurança jurídica que garante no cumprimento das normas legais, bem como, na utilização do recursos públicos, visando o bem coletivo.
\end{abstract}

Palavras chave: Controladoria Geral; Planejamento Público; Município de Curaçá.

\section{Performance of the General Controllership in the Municipal Public Planning: Analysis of the General Controllership of Curaçá in Bahia}

\begin{abstract}
The study had as objective to analyze the performance of the General Controllership in Municipal Public Planning, having as central study the city of Curaçá. To support the study, we used exploratory, bibliographic, documentary and field research. Collecting the data through the application of a questionnaire, directed to servers that occupied the position of General Controller of the Municipality, between the period from 2009 to 2018. Bringing the experience of those who occupied, in that period. It is possible to conclude on the performance of the Controllership in the Planning process of the instruments that give subsidy to the Municipal management, does not obey to the legal precepts, considering that the Controllership does not participate in an effective form of Planning, lacking that from this research, to take another look at the important task that the Controller General exercises, mainly in the legal security that guarantees in the compliance with legal norms, as well as in the use of public resources, aiming at the collective good.
\end{abstract}

Keywords: General Controllership; Public Planning; Municipality of Curaçá

\footnotetext{
${ }^{1}$ Universidade Federal do Vale do São Francisco - UNIVASF. Contato: silvana.paixao@ gmail.com.
} 


\section{Introdução}

Atualmente, nas circunstâncias em que se encontra a administração pública, a ausência de recursos e a má administração tem favorecido de forma significativa o desperdício e a corrupção, proveniente da ausência e a fragilidade dos controles na administração. Tendo como consequente a exigência da sociedade sobre os administradores públicos em relação à existência de um controle mais eficaz, já que nos últimos anos a transferência de responsabilidades de atribuições da união e dos Estados para os Municípios, veem aumentando a preocupação com a melhor utilização dos recursos públicos, levando os municípios a buscarem uma melhor profissionalização, afim de promoverem excelência na fiscalização contábil, financeira, orçamentária e patrimonial.

Os municípios carecem de maior efetividade na transformação dos recursos públicos em prestação de serviços essenciais as necessidades básicas dos seus habitantes, logo existem uma premente necessidade de se melhorar os gastos com o dinheiro público, para que sejam alcançados os seus objetivos.

Com isso, surge a necessidade de se criar um mecanismo que realizasse esse controle, permitindo que a administração se efetivasse no que diz respeito a gerência dos recursos públicos, cuidando para que esses fossem melhor destinados, ou que no mínimo, fossem adequadamente utilizados.

Sendo instituído com o fim de aperfeiçoar continuamente o Serviço Público, verificando as atividades exercidas pelos órgãos, o cumprimento das leis e contribuindo para o planejamento, o Controle Interno é o conjunto de atividades e métodos utilizados com vistas a garantir que as entidades públicas da administração atinjam, de forma segura e concreta, os resultados pretendidos, evidenciando eventuais irregularidade ao longo da gestão, até da consecução dos desígnios fixados pelo Poder Público.

No que se refere ao Planejamento, a Controladoria contribui para o aperfeiçoamento contínuo da instituição, verificando as atividades exercidas pelos órgãos, o cumprimento das leis e contribuindo para a execução da receita e despesa de acordo com aquilo que foi previamente planejado. Auxiliando os gestores, diretamente para a proteção e defesa do cidadão e para que os objetivos da organização pública sejam alcançados. 
A Lei Municipal $n^{\circ}$ 483/2006 de 23 de outubro de 2016, deu origem a Unidade de Controle Interno no Município de Curaçá, mas nunca foi implantado nos termos da sobredita lei, tendo sido reformulada pela Lei Municipal $n^{\circ}$ 715/2017, de 11 de janeiro de 2017, atendendo ao mandamento da norma constitucional.

A fim de atingir o objetivo deste estudo, tendo como metodologia a pesquisa bibliográfica com consulta em livros, autores, e outros, e ainda a aplicação de um questionário, destinado a servidores que ocuparam nos últimos dez anos, o cargo de Controlador Municipal.

Tendo como objetivo principal, analisar a participação da Controladoria Geral do Município, no processo de Planejamento Público. Discutindo mecanismos de controle dentro da administração pública, seja nas áreas: financeira ou meramente administrativa.

A Lei de Responsabilidade Fiscal imputa à contabilidade pública nova funções na influência orçamentária e financeira, afiançando-lhe um caráter mais gerencial. Assim, com o advento da Lei de Responsabilidade Fiscal, os subsídios passarão a interessar não apenas à administração pública e aos seus gestores, mas também a sociedade se torna participante do processo de acompanhamento e fiscalização das contas públicas mediante os instrumentos que a Lei de Responsabilidade Fiscal incorpora para esta finalidade.

Portanto, em um primeiro momento, trataremos dos conceitos e institutos que cercam a atividade da Controladoria Geral, bem como, acerca do Planejamento Público.

Na sequência, serão expostos informações sobre a atuação da Controladoria Geral no Município de Curaçá, para ao final, na análise dos dados apresentar as informações obtidas através do questionário, que é parte do presente estudo.

\section{Controle na Administração Pública}

A expressão controle é de origem francesa, e significa vigiar, constatar, examinar e supervisionar. Figurando dentro dos princípios primordiais da administração, é tanto que a sua inexistência ou deficiência gera para a Administração Pública, resultados negativos nas demais funções (planejamento, organização, direção e coordenação), resultando na ineficácia e ineficiência da organização.

Para Meirelles (2017, p. 629): 
Controle Administrativo é todo aquele que o executivo e os órgãos de administração dos demais Poderes exercem sobre suas próprias atividades, visando a mantê-las dentro da lei, segundo as necessidades do serviço e as exigências técnicas e econômicas de sua realização, pelo que é um controle de legalidade e de mérito.

As Constituições Brasileiras passadas também evidenciavam preocupações com o controle de legalidade dos atos da administração, distinguindo sua importância para uma boa gestão.

Passando, a partir da Constituição Federal de 1988, o controle passou a ter maior enfoque em fiscalizar, evidenciando-se, assim, sua qualidade de instrumento precípuo para o processo decisório e o direcionamento das ações governamentais delineadas, via planejamento.

O conhecimento dos atos e fatos administrativos em um momento curto de tempo, por interferência das novas tecnologias informacionais, pode ser um admirável mecanismo de realização do controle social nos municípios”, (FILHO, 2018, p. 86).

Portanto, o controle pode ser feito com base na forma utilizada para a prática dos atos ou sobre o resultado apurado, formalidade que tem como responsável o gestor/executor, aquele que responde nos tribunais por praticar atos de acordo com a lei; enquanto o controle de resultado sobre o produto (serviços fornecidos à população) está a cargo do gestor/responsável (gerente), mais preocupado com a pertinência do gasto e que responde pelos resultados do orçamento.

A verdade é que o Controle assumiu um papel admirável na administração, impondo perímetros à atuação do governo e dirigindo a melhor utilização dos recursos disponíveis de forma constituída e ponderada.

Cruz e Glock (2007, p. 19),

O ato de controlar está intimamente ligado ao de planejar. Dá retorno ao processo de planejamento e visa garantir que, através da aplicação dos recursos disponíveis, algum resultado seja obtido, seja na forma de produto ou de serviço.

No caso da área pública, dentre os resultados a serem obtidos com os procedimentos de controle, enfatiza-se a garantia de que os aspectos legais estão sendo rigorosamente observados.

Neste sentido, avalia-se o controle da administração como sendo o conjunto de mecanismos jurídicos por meio dos quais se exerce o poder de fiscalização e de revisão da atividade administrativa em qualquer dos domínios de Poder. Tendo como objetivo, digamos 
primordial garantir que a Administração pública opere em conformidade com os princípios que lhe são impostos pelo ordenamento jurídico, como os da:

\footnotetext{
"legalidade, moralidade, finalidade pública, publicidade, motivação, impessoalidade; em apontadas circunstâncias, abrange também o controle chamado de mérito e que diz respeito aos aspectos discricionários da atuação administrativa" (MEIRELLES, 2017, p. 179).
}

Tem-se o controle interno quando a própria Administração Pública procede ao controle sobre suas próprias ações, procedendo do poder hierárquico que a organiza, pois é o desenho que a Administração tem para verificar a legitimidade e a legalidade de seus próprios atos, no sentido de se ater aos princípios da legalidade e da supremacia do interesse público, em que se inclui, avaliação abarcando a conveniência administrativa do ato praticado.

O Controle, além da sua obrigatoriedade decorrente da legislação brasileira, é de extrema seriedade para impedir que a Administração Pública se distancie dos objetivos e empenhos públicos, bem como desatenda aos princípios e as normas legais.

No âmbito municipal, é exigida a existência de um sistema de controle interno, tendo em vista que o sistema normativo da Fiscalização Contábil, Financeira e Orçamentária, assegurada nos artigos 70 a 75 da Constituição Federal que possui extensão de aplicabilidade aos municípios, por força do regramento contido no artigo 31 da Carta Magna: “A fiscalização do Município será exercida pelo Poder Legislativo Municipal, mediante controle externo, e pelos sistemas de controle interno do Poder Executivo Municipal, na forma da lei”.

Neste sentido, os municípios devem manter sistemas de controle interno para o cumprimento das atribuições estipuladas no artigo 74 da Constituição, com a peculiaridade de esses sistemas ficarem a cargo do Poder Executivo Municipal, cujo exercício deverá ocorrer na forma da lei, sobre toda a Administração municipal.

O controle interno deve ser instituído e organizado de forma única, mas com composição sistêmica, cuja constituição do sistema-pessoal, contabilidade, auditoria etc., atuem de maneira coordenada, sob a direção de uma central de controle interno, que terá pertinência sobre os dois Poderes do Município.

Na Lei de Responsabilidade Fiscal continua-se preocupação em identificar receitas disponíveis à União, aos Estados e Municípios para a concretização de despesas com pessoal, desperdiçados com serviços de terceiros e pagamento de dividas. 
Assim, o controle interno agirá, nos termos da inspeção contábil, financeira, orçamentária, funcional e patrimonial no sentido de analisar o cumprimento da metas previstas no nível plurianual e a execução dos programas de governos e dos orçamentos; evidenciar a legalidade e ponderar as implicações, quanto à eficácia e eficiência da gestão orçamentária, financeira e patrimonial; exercer o domínio das operações de confiabilidade e dar apoio ao controle externo no aprendizado da sua missão institucional.

Contudo, para os municípios não há que se falar em controle interno próprio para o Poder Legislativo, por absoluta inviabilidade constitucional. Para tanto, a instituição e organização do sistema de controle interno serve para controlar o Prefeito Municipal, por isso, não tem interesse de assim proceder, porque não pretende se submeter ao controle de subordinados seus.

A fiscalização financeira e orçamentária no âmbito municipal alcança-se mediante controle externo da Câmara de Vereadores, com o subsídio do Tribunal de Contas dos Estados ou do Município ou dos Conselhos ou Tribunais de Contas dos Municípios, onde possuir, e controle interno do Executivo Municipal (LRF, artigo, 59), na forma da lei (CF, artigo, 31 e seguintes).

\section{Tipos de Controle}

Na Administração Pública, podemos citar como tipos de Controle, como internos e externos, ambas tem como função fiscalizar, ser agente orientador e provocar os entes a corrigir seus atos.

As tipos de controle, a nível municipal, estão ligados diretamente à sua atuação, são eles: o controle externo, exercício pelos órgãos auxiliares e o controle interno, que possui uma atuação direta nos atos controlados. (BOTELHO, 2014)

Dessa forma, percebe-se que o Controle Interno e Externo podem atuar de forma harmoniosa, mesmo não havendo subordinação hierárquica, tendo em vista que não existe qualquer dispositivo que obrigue o Tribunal de Contas acatar o Relatório da unidade central das Controladorias, apenas, as informações trazidas, subsidiarão na atividade de análise da prestação de contas pelos técnicos. 
Podemos definir que o controle externo é realizado por órgão estranho a Administração Pública, responsável pelo ato controlado, no caso a Câmara Municipal com o auxilio do Tribunal de Contas.

Os órgãos de controle externo poderão solicitar apoio do Controle Interno no exercício de sias missões institucionais, conforme preceitua o IV do art. 74 da Constituição Federal de 1988. Sendo órgãos do controle externo:

$$
\begin{aligned}
& \text { - } \quad \text { Câmara de Vereadores; } \\
& \text { - } \quad \text { Mininistério Público; } \\
& \text { - } \quad \text { Sociedade. (BOTELHO, 2014). }
\end{aligned}
$$

Assim, é interno aquele realizado pela entidade ou órgão responsável pela atividade controlada, no âmbito da própria administração, exercício de forma adequada, capaz de propiciar uma razoável margem de garantia de que os objetivos e metas serão atingidos de maneira eficaz, eficiente e com a necessária economicidade, a exemplo da Controladoria Geral.

Um bom sistema de controle se transforma em instrumento auxiliar de gestão e deve estar direcionada a todos os níveis hierárquicos da administração. (BOTELHO, 2014).

\section{Formas de Controle}

Pode-se afirmar, que as Controladorias inauguraram nos órgãos internos da Administração, maior efetividade ao controle exercido, tendo em vista a insuficiência da forma hierarquizada de controle.

Ainda não se apresentando como suficiente, tendo em vista que o controle pode ser exercido por servidor integrante da Administração Pública, dado os aspectos como a vinculação intersubjetiva com o agente público responsável pelo ato administrativo submetido ao controle interno, essa situação pode interferir na imparcialidade do agente controlador.

A despeito dessas duas formas de controle externo, a Constituição Federal possibilita aos cidadãos o controle social sobre a Administração Pública. A sociedade pode interferir e fiscalizar as atividades exercidas pelo Estado e os atos dos administradores públicos. Trata-se de forma de participação popular no atuar administrativo, decorrência obrigatória da concepção 
de Estado Democrático. Nada mais adequado que a sociedade controle os gestores públicos, eleitos para a finalidade de consecução do interesse público.

Decorre da necessidade constante de interferência da sociedade na gestão do patrimônio público.

\title{
A Responsabilidade na Prática de Controle Interno na Administração Municipal
}

Castro (2008, p. 54) apresenta que o controle interno ou controle interno administrativo é:

\begin{abstract}
Antes de tudo, a segurança do administrador. É fundamental, em primeiríssimo lugar, para o gestor público, porque este responde - com seus bens e sua reputação - pelos atos que realiza e deve, portanto, praticá-los com toda segurança possível. Portanto, o administrador precisa do controle em todos os níveis e de forma prévia de modo a dar suporte a todos os seus atos decisórios.
\end{abstract}

Dentre as funções que o controle interno possui, tem-se a proposição de padronização e a organização dos procedimentos de cada unidade, em especial a estrutura dos instrumentos de planejamento que deverão estar plenamente de acordo com a Estrutura Organizacional, entretanto, a implantação dos procedimentos e rotinas do sistema de controle interno, deverá estar adequada à Estrutura Organizacional, consequentemente o relatório anual integrará a prestação de contas.

Carecendo que haja maior segurança quanto aos documentos que diariamente são protocolados para apreciação do órgão. Assim como, as normas e procedimentos do sistema de Controle Interno no âmbito da administração direta e indireta deverão ser instituídos por Decreto do Chefe do Executivo, considerando que os efeitos dos procedimentos serão externos.

De acordo com Botelho (2014, p. 275),

A ausência de um sistema de controle interno eficaz nos municípios se dá por várias razões, como: A falta de iniciativa do administrador; Falta de planejamento adequado; Falta de estrutura organizacional atualizada; Ausência de controle nas unidades administrativas; Falta de recursos humanos; Conluio de agentes; Remuneração não condizente com as responsabilidades; Ausência de procedimentos e rotinas; Resistência às mudanças por parte dos servidores.

A transparência da gestão pública estabelece o estímulo à participação popular e à concretização de audiências públicas, tanto durante a preparação como no decorrer da discussão dos planos, da Lei de Diretrizes Orçamentárias e dos Orçamentos. 
A Constituição Federal no artigo $31, \S 3^{\circ}$, reza que:

Art. 31. A fiscalização do Município será exercida pelo Poder Legislativo Municipal, mediante controle externo, e pelos sistemas de controle interno do Poder Executivo Municipal, na forma da lei.§ $3^{\circ}$ - As contas dos Municípios ficarão, durante sessenta dias, anualmente, à disposição de qualquer contribuinte, para exame e apreciação, o qual poderá questionar-lhes a legitimidade, nos termos da lei.

\section{Controladoria Geral do Município de Curaçá}

Instituída pela Lei Municipal no 486/2006, de 23 de outubro de 2006, recentemente alterada pela Lei Municipal $n^{\circ} 715 / 2017$, de 11 de janeiro de 2017, a Controladoria Geral do Município de Curaçá tem como quadro O Controlador Geral, uma secretária de Gabinete e uma subcontroladoria.

De acordo com Botelho (2014, pág. 27)

A Controladoria Geral do Município - Órgão Central de Controle Interno do Poder Executivo, com total autonomia funcional, responsável pela expedição de atos normativos e regulamentadores dos procedimentos de controle - unidade administrativa para integrar os procedimentos de controle e fiscalização e ainda consolidar as informações de gestão orçamentária, financeira, patrimonial e operacional, com a finalidade de atestar a legalidade, a legitimidade, a economicidade, a eficiência e a eficácia dos programas de governo - categoria administrativa.

A Controladoria Geral da Prefeitura Municipal de Curaçá desde a sua criação, não atende aos preceitos legais, sob vários aspectos, sendo os principais a estrutura física adequada e corpo técnico capacitado para atuar de forma eficiente e eficaz.

O trabalho exercício pela Controladoria vem prevenindo a gestão contra gastos abusivos e excessivos, e ainda ocorre a fiscalização da atuação dos agentes públicos e políticos. Desde a sua criação, são rotineiros os problemas:

a) Não há sintonia entre o setor financeiro e a Controladoria, ou seja, geralmente os processos só chegam a este setor depois que a despesa já foi realizada, quando deveria passar antes pelo crivo do controlador para saber se a mesma cumpre os preceitos da Lei $n^{\circ}$ 4.320/64 e da LC 101/2000 (LRF), no que tange ao cumprimento do estágio da despesa;

b) Não há planejamento das ações quanto à execução orçamentária, ou seja, não existe controle sob o ciclo orçamentário que possa auxiliar o gestor na tomadas de decisões; 
c) A Controladoria tem dificuldade para acompanhar a evolução patrimonial, tendo em vista a falta de controle na conta almoxarifado;

d) Há uma centralização das ações por parte da Secretaria de Finanças, ou seja, a maioria dos processos de despesas são gerados e liquidados diretamente pela Secretaria de Finanças e em sua maioria não são submetidos à verificação e análise da Controladoria em tempo hábil;

e) Não há uma avaliação eficiente do cumprimento das metas previstas no Plano Plurianual, a execução dos programas de governo, e execução do orçamento anual;

f) A Controladoria é vista como segundo plano pela administração. Percebe-se que o setor da Prefeitura de Curaçá mesmo tendo sido instituído por Lei Municipal, funciona precariamente de forma improvisada, deficitária e não exerce plenamente o controle e a fiscalização das contas públicas, nos termos preconizados pelos artigos 31, 70 e 74 da Constituição Federal e parágrafo único do artigo 54 da Lei Complementar 101, de 4 de maio de 2000. Nota-se que o município apesar de a lei definir as finalidades da Controladoria, essas na prática ainda não se enquadram ao que dispõe o artigo 74 da Constituição Federal, que trata das competências do sistema de controle interno na esfera federal.

\section{Instrumentos do Planejamento Público}

Dentre as atividades especificas da Controladoria Geral, está a de incentivar o cumprimento dos programas do governo certificando que tudo esteja autorizado por lei e vinculado aos objetivos de sua criação. Realizar confronto entre os dados constantes dos instrumentos der planejamento (PPA, LDO e LOA) e a execução orçamentária, certificando a execução de obras planejadas, se estão sendo realizadas de acordo com o programa físicofinanceiro, se as receitas estão sendo arrecadadas dentro dos valores estabelecidos no cronograma mensal de desembolso, são obrigações frequentes.

A constituição de 1988 estabeleceu em seu art. 165 os três instrumentos de planejamento da administração pública. O plano Plurianual - PPA, a Lei de Diretrizes Orçamentárias - LDO, e a Lei Orçamentária Anual - LOA, compondo assim o sistema orçamentário. (BOTELHO, 2014, PÁG. 231).

De forma resumida, passaremos a expor sobre cada um dos instrumentos.

\section{Plano plurianual - PPA}

Denomina-se Plano Plurianual ou PPA, o instrumento de governo utilizado para o planejamento estratégico de médio prazo da administração pública brasileira. É largamente 
considerado pelos doutrinadores uma das principais peças da composição orçamentária, e tem por finalidade, conforme, Carvalho, D. (2007, p. 28), estabelecer de forma regionalizada as Diretrizes, Objetivos e Metas (DOM) da administração.

A elaboração do PPA permite decidir quais são os investimentos mais importantes a serem realizados dentro dos objetivos traçados com vistas ao desenvolvimento, sobretudo, Municipal. No Manual Técnico de Orçamento - MTO, elaborado pelo Ministério do Planejamento, Orçamento e Gestão - MPOG, estão estabelecidas as políticas, diretrizes, metodologia e procedimentos para a elaboração dos orçamentos, além do que, os princípios básicos que norteiam o PPA:

- Identificação clara dos objetivos e prioridades do Governo;

- Integração do planejamento e do orçamento;

- Promoção da gestão empreendedora;

- Garantia da transparência;

- Estímulo às parcerias;

- Gestão orientada para resultados; e;

- Organização das ações do Governo em programas (CARVALHO, D., 2007, p. 28).

O PPA foi instituído na Constituição Federal de 1988, surgiu como um termo inovador, substituindo as antigas denominações: Plano Plurianual de Investimentos ou Plano Nacional de investimentos. É uma Lei que abrangerá os respectivos entes da Federação: A União, os Estados, o Distrito Federal e os Municípios.

Sua elaboração acontece no primeiro ano do mandato do Executivo e terá vigência de quatro anos, compreendida entre o segundo ano de um mandato e o primeiro ano do mandato subsequente, é, portando, uma Lei temporária, onde a disposição de sua vigência fica a cargo de Lei Complementar. De acordo com a Constituição Federal, Art. 165, § 9: § $9^{\circ}$ :

Cabe à lei complementar: I - dispor sobre o exercício financeiro, a vigência, os prazos, a elaboração e a organização do plano plurianual, da lei de diretrizes orçamentárias e da lei orçamentária anual; (CF, 1988).

O período estipulado para vigência do PPA faz com que haja uma defasagem ocasionada para o primeiro ano de cada mandato, posto que, no primeiro ano de cada governo ainda não se tem um orçamento genuíno. Convêm-se que esse período se reserva ao executivo para que inicie a elaboração de seu próprio plano de trabalho. Neste espaço de tempo, coincidente com o primeiro ano da gestão, o executivo presumidamente da continuidade ao que focou pendente de aplicação do orçamento da gestão anterior. 
Os planos plurianuais substituíram os planos nacionais de desenvolvimento, e sua vigência corresponderá ao mandato presidencial (que, com a Emenda Constitucional de Revisão $n^{\circ} 5 / 94$, voltou a ser de quatro anos), sempre com um ano de defasagem (isto é, do $2^{\circ}$ ano do mandato de cada presidente ao $1^{\circ}$ do mandato subsequiente) (PISCITELLI et al, 2002, p. 48).

Estabelecido o planejamento orçamentário, resta proceder o encaminhamento aos órgãos competentes para apreciação, neste caso, o legislativo. Dispondo sobre isso, a Constituição Federal de 1988 em seu $§ 2^{\circ}$ do artigo 35 do Ato das Disposições Constitucionais Transitórias - ADCT estabeleceu o seguinte:

a) Para o plano (plurianual):

- Encaminhamento - até quatro meses antes do encerramento do primeiro exercício financeiro de cada mandato presidencial;

- Devolução para sanção - até o encerramento da respectiva sessão legislativa;

- Período de execução - do início do segundo exercício financeiro do mandato presidencial até o final do primeiro exercício financeiro do mandato subsequente (PISCITELLI et al, 2002, p. 74). 2.2.4.2.

\section{Lei de diretrizes orçamentárias - LDO}

Se o PPA é considerado estratégico para o governo, a Lei de Diretrizes Orçamentárias - LDO é operacional, assim como a Lei Orçamentária Anual. Em sua proposta fundamental irá orientar a elaboração orçamentária, definindo quais serão as prioridades e metas do PPA para o exercício financeiro subsequente.

A LDO compreenderá as metas e prioridades da administração pública federal, estadual e municipal, incluindo as despesas de capital para o exercício financeiro subseqüente, orientará a elaboração da lei orçamentária anual, disporá sobre as alterações na legislação tributária e estabelecerá a política de aplicação das agências financeiras oficiais de fomento.

Com a vigência da Lei de Responsabilidade Fiscal (LRF), de acordo com o art. $4^{\circ}$, cabe a LDO dispor sobre o que rege o $\S 2^{\circ}$ do art. 165 da Constituição Federal de 1988:

Art. 4o A lei de diretrizes orçamentárias atenderá o disposto no $§ 20$ do art. 165 da Constituição e:

I - disporá também sobre:

a) Equilíbrio entre receitas e despesas; 
b) Critérios e forma de limitação de empenho, a ser efetivada nas hipóteses previstas na alínea $\mathrm{b}$ do inciso II do art. $4^{\circ}$, no art. $9^{\circ}$ e no inciso II do $\S 1^{\circ}$ do art. 31 da LRF;

c) Normas relativas ao controle de custos e à avaliação dos resultados dos programas financiados com recursos dos orçamentos;

d) Demais condições e exigências para transferência de recursos a entidades públicas e privadas. (CF, 1988).

O art. $2^{\circ}$ da Constituição Federal de 1988 estabelece:

$\S 2^{\circ}$ - A lei de diretrizes orçamentárias compreenderá as metas e prioridades da administração pública federal, incluindo as despesas de capital para o exercício financeiro subseqüente, orientará a elaboração da lei orçamentária anual, disporá sobre as alterações na legislação tributária e estabelecerá a política de aplicação das agências financeiras oficiais de fomento. (CF, 1988).

Integrarão, ainda, a LDO os anexos de metas fiscais e de riscos fiscais estabelecidos nos $\S \S 1^{\circ}$ e $3^{\circ}$ do art. $4^{\circ}$ da LRF.

\begin{abstract}
§ 1o Integrará o projeto de lei de diretrizes orçamentárias Anexo de Metas Fiscais, em que serão estabelecidas metas anuais, em valores correntes e constantes, relativas a receitas, despesas, resultados nominal e primário e montante da dívida pública, para o exercício a que se referirem e para os dois seguintes. § 3o A lei de diretrizes orçamentárias conterá Anexo de Riscos Fiscais, onde serão avaliados os passivos contingentes e outros riscos capazes de afetar as contas públicas, informando as providências a serem tomadas, caso se concretizem (LRF, 2000).
\end{abstract}

Segundo Piscitelli (2002, p. 74), reza a CF/88 em seu $\S 2^{\circ}$ do artigo 35 do Ato das Disposições Constitucionais Transitórias - ADCT, que para a LDO fica estabelecido:

b) Para as diretrizes orçamentárias (anual):

- Encaminhamento - até oito meses e meio antes do encerramento de cada exercício financeiro;

- Devolução para sanção - até o encerramento do primeiro período da correspondente sessão legislativa;

- Período de aplicação específica: exercício financeiro correspondente ao do orçamento que será elaborado e executado com base na respectiva lei de diretrizes orçamentária.

\title{
Lei orçamentária anual - LOA
}

Compreende o orçamento referente às esferas governamentais da União, Estado, Municípios, seus fundos, órgãos e entidades da Administração direta e indireta, inclusive fundações instituídas e mantidas pelo Poder Público, também da seguridade social, e abrangendo todas as suas entidades. 
A lei orçamentária deverá ser compatível com o PPA e com a LDO vigentes.

A transparência será assegurada também mediante incentivo à participação popular a realização de audiências públicas, durante os processos de elaboração e de discussão dos planos, lei de diretrizes orçamentárias e orçamentos. (BRASIL, 2010).

Segundo Piscitelli (2002, p. 74), reza a CF/88 em seu $\S 2^{\circ}$ do artigo 35 do Ato das Disposições Constitucionais Transitórias - ADCT, que para a LOA fica estabelecido:

c) Para o orçamento (anual):

- Encaminhamento - até quatro meses antes do encerramento de cada exercício financeiro;

- Devolução para sanção - até o encerramento da correspondente sessão legislativa;

- Período de execução - exercício financeiro relativo ao ano-calendário de sua respectiva execução.

O projeto para a Lei Orçamentária Anual é de responsabilidade do chefe do executivo, contudo, para aplicar o seu plano de trabalho em conformidade com a expressa lei, o executivo se sujeita ao cumprimento de prazo fixado, conferindo ao legislativo uma elevada importância configurada, segundo Silva, nas seguintes fases e respectivas operações:

a) Iniciativa - Embora a iniciativa seja do chefe do executivo, o mesmo está o mesmo está obrigado ao prazo fixado. Se o titular do executivo não a exercer ou não cumprir o tempo determinado pela Constituição, ocorre o crime de responsabilidade;

b) Discussão - é a fase dos trabalhos consagrada ao debate em plenário;

c) Sanção - é definida como a aquiescência do titular do Poder Executivo ao projeto de lei aprovado pelo Poder Legislativo.

d) Veto - se o titular do poder executivo não estiver de acordo, poderá vetar total ou parcialmente o projeto de lei, dentro de 15 dias úteis contados do recebimento do projeto, comunicando ao presidente do Senado Federal os motivos do veto.

e) Promulgação e publicação - o projeto de lei é transformado em Lei (SILVA, 2000, p. 67).

As etapas por qual se define o orçamento público se converge continuamente de tempos em tempos com períodos prefixados, segundo os quais os orçamentos são preparados, votados, executados, os resultados avaliados e as contas finalmente aprovadas. Ao final de todas estas etapas temos completo o ciclo orçamentário, o que corresponde ao período em que se processam as atividades inerentes ao plano orçamentário.

\section{Mecanismos de retificação do orçamento público}


Os três instrumentos legais PPA, LDO e LOA, determinados pela Constituição Federal, se configuram como um contrato orçamentário que deverá ser executado em benefício dos cidadãos e da cidade, cabendo em última instância à responsabilidade ao prefeito do município em executá-lo. Contudo, conforme Fazzi (2010, p. 34), “como qualquer outro, o contrato orçamentário firmado entre o prefeito e a sociedade corre também o risco de ser rompido".

A motivação para tanto, desde que tenha sido verificada entre o orçamento e a realidade de receitas e despesas uma diferença excessiva, faz-se por negligência ou imperícia na elaboração do orçamento, ou ainda, pelo cometimento de crime de responsabilidade. Entretanto, se a elaboração é criteriosa e ainda assim os valores não tangenciaram as previsões orçadas, devem-se levar em consideração as mudanças inesperadas que podem ocorrer na política econômica e fiscal, considerada normal aos olhos da legislação orçamentária brasileira.

O fato é que de algum modo o orçamento pode deixar de se cumprir em sua totalidade e o mecanismo legal para corrigir o decurso das ações planejadas é a abertura de créditos adicionais.

O crédito adicional é um meio legal de ajuste do orçamento, utilizado para amenizar ou corrigir distorções identificadas durante a execução orçamentária, por exemplo, excesso de créditos alocados em determinadas dotações e insuficiências em outras. Corresponde, em síntese, às autorizações de despesas não-computadas ou insuficientemente dotadas na lei orçamentária” (ARAÚJO, 2004, p. 161).

A Lei 4.320/1964 em seu artigo 41 classifica o crédito adicional em três espécies, a saber:

I - suplementares, os destinados a reforço de dotação orçamentária;

II - especiais, os destinados a despesas para as quais não haja dotação orçamentária específica;

III - extraordinários, os destinados a despesas urgentes e imprevistas, em caso de guerra, comoção intestina ou calamidade pública (BRASIL, 2010).

O decreto do executivo é o ato que determina a abertura de todos os créditos adicionais, porém, os créditos, especial e suplementar, necessitam de prévia autorização do legislativo, que por sua vez precisa que o executivo aponte os recursos disponíveis que compensarão a abertura dos respectivos créditos, cumprindo assim uma exigência constitucional.

O contrário desta exigência se faz com a abertura de crédito extraordinário, calçado pelo próprio caráter de urgência em decorrência de despesas urgentes e imprevisíveis, segundo o 
artigo 167, $\S 3^{\circ}$, da $\mathrm{CF}$, em caso de guerra, comoção interna ou calamidade pública, e conforme o artigo 44 da Lei 4.320/1964, “... abertos por decreto do Poder Executivo, que deles dará imediato conhecimento ao Poder Legislativo".

Segundo Araújo (2004, p.161), consideram-se recursos disponíveis, para o fim desses créditos, desde que não comprometidos:

- O superávit financeiro;

- Os provenientes de excesso de arrecadação;

- Os resultados de anulação parcial ou total de dotações orçamentárias ou de créditos adicionais autorizados em lei;

- O produto de operações de crédito autorizadas.

Nesse processo que visa corrigir as situações inesperadas e que demandam alterações no planejamento previamente realizado, o papel da Controladoria se torna crucial, tendo em vista a necessidade de análise e estudo, uma vez que o planejamento deve, sempre, atender ao interesse da coletividade, ou seja, de toda uma sociedade.

\section{Método}

A presente pesquisa tem como universo de amostra a Controladoria Geral do Município de Curaçá/BA. Tendo como objetivo geral, analisar o Sistema de Controle Interno do Município, sob a ótica de cumprimento do que determina a legislação, sobre a sua estrutura e atividade, analisando a legislação pertinente, princípios e relatórios de execução.

Para isso foi necessário aplicar, na construção deste trabalho, uma pesquisa descritiva, já que não interferirá no processo. Segundo Trivinõs (1987, p. 112) “a pesquisa descritiva exige do investigador uma série de informações sobre o que deseja pesquisar". Esse tipo de estudo pretende descrever os fatos e fenômenos de determinada realidade. Como procedimento será utilizada a pesquisa bibliográfica, para explicar e comparar a problemática a partir dos referenciais teóricos publicados que tendem a refletir em seu aspecto futuro.

Trata-se de uma pesquisa qualitativa quanto à abordagem do problema, visto que a intenção é analisar a atuação do Controle Interno no Município de Curaçá. Conforme Goldenberg, 1997, p. 34, “a pesquisa qualitativa não se preocupa com representatividade numérica, mas, sim, com o aprofundamento da compreensão de um grupo social, de uma organização". 
Este estudo não tem a intenção de abranger um universo de hipóteses técnicas existentes inerentes aos controles internos, mas apenas apontar de que forma o Sistema contribui para eficiência na gerência dos recursos públicos e se este alcança de fato, seu objetivo que é contribuir para que os caminhos para a organização da Administração Pública ocorra.

\section{Coletas, Análises e Interpretação de Informações:}

Objetivou-se, a partir dos referenciais teóricos, investigar por meio de obras e trabalhos publicados os fundamentos legais de atuação das Controladorias Gerais, correlacionando-os com os aspectos do controle dos atos públicos, na busca de uma administração mais eficiente.

Para subsidiar os trabalhos serão utilizadas informações da atuação do Sistema de Controle, normas, atos, relatórios, plano de auditoria, dentre outros, bem como, as secundárias, as quais serão obtidas mediante pesquisas na legislação correspondente, pesquisas em livros, artigos, sites da internet e dissertações que tratam da atuação e importância da Controladoria Geral no Planejamento Público Municipal, necessários para subsidiarem a problemática.

\section{Análise dos Resultados}

\section{Caracterização do Município}

O município de Curaçá, com população estimada de 35.524 habitantes (IBGE 2017) e de acordo com o Instituto Brasileiro de Geografia e Estatística (IBGE - 2017) Curaçá está localizada no norte do estado da Bahia, possuindo uma área territorial de $6.079,022 \mathrm{~km}^{2} \mathrm{e}$ densidade demográfica de 5,29 habitantes $/ \mathrm{km}^{2}$. Faz fronteira com os municípios de Juazeiro, Jaguarari, Andorinha, Monte Santo, Uauá, Chorrochó e Abaré, é constituído de 04 distritos (Barro Vermelho, Patamuté, Poço de Fora e Riacho Seco) e diversos povoados e vilas. Atualmente o município possui como código no IBGE 2909901 e Índice de Desenvolvimento Humano Municipal - 2010 (IDHM 2010) de 0,581.

O município de Curaçá possui uma população de 32.168 habitantes de acordo com IBGE 2010 e uma estimativa para 2017 de 35.524 habitantes, no qual há um maior predomínio da 
população residente na zona rural $(57,35 \%)$ e $51,18 \%$ dessa população é do sexo masculino, conforme gráfico abaixo:

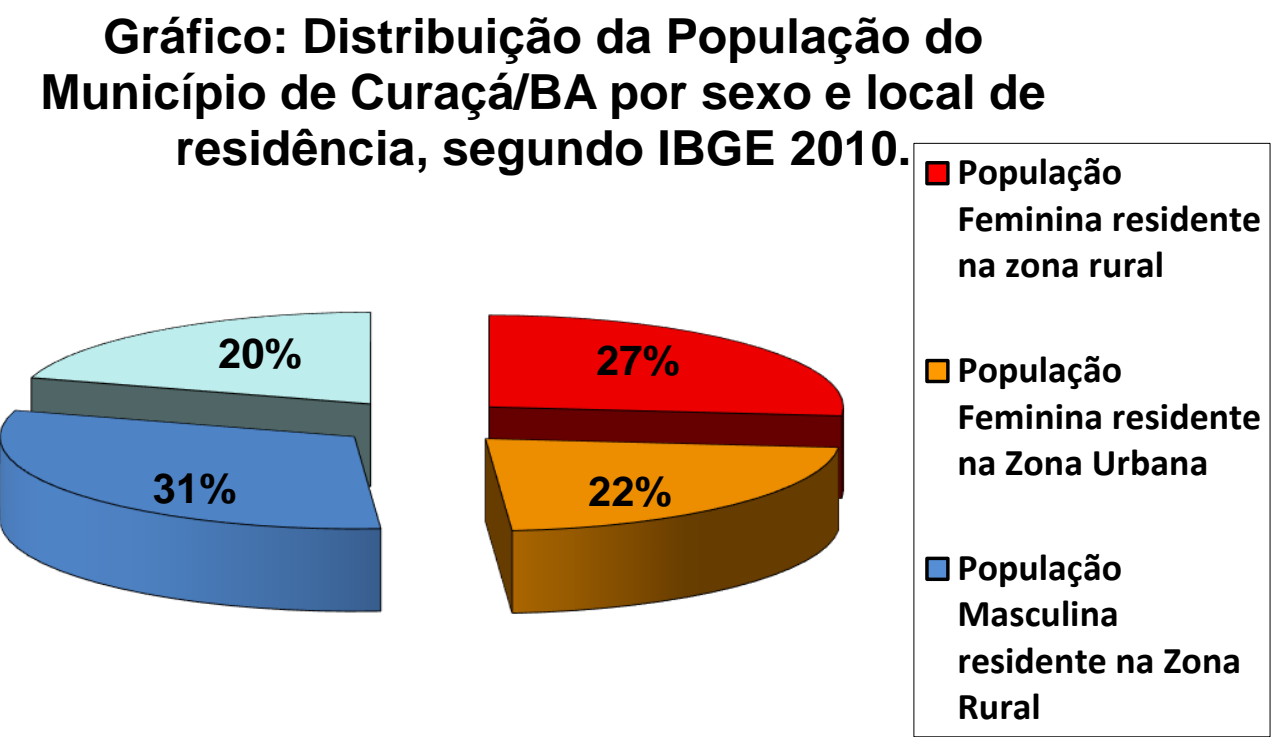

\section{Perfil dos Participantes}

O questionário foi submetido a profissionais que exerceram do ano de 2009 a 2018, o cargo de Controlador Interno, atualmente, Controlador Geral do Município. Cada um, relatando situações pelas quais vivenciaram.

Sendo 1 do sexo masculino, Fanilo Irmes Torres de Oliveira, graduado em direito e 3 do sexo feminino, a primeira Marinalva Paixão De Oliveira, formada em técnico de contabilidade, a segunda Silvana Rodrigues Paixão, graduada em direito e a terceira Adelita da Mota Lopes, formada em administração.

\section{Participação no Processo de Planejamento Público}

A Controladoria Geral da Prefeitura Municipal de Curaçá, assim como boa parte dos Municípios no Brasil, não atende completamente os preceitos da Lei de Responsabilidade fiscal, 
uma vez que, não dispõe de estrutura física adequada, nem tampouco corpo técnico capacitado para atuar de forma eficiente e eficaz, principalmente no que se refere ao Planejamento Público.

Dentro das suas atividades, participa da elaboração do Planejamento Financeiro do Município, gerencia o Sistema da Dívida Pública Municipal e o Sistema de Execução orçamentária, financeira e contábil patrimonial dos órgãos e entidades da Administração Direta e Indireta e opera na arrecadação e fiscalização dos tributos e demais rendas do fisco.

Com o presente estudo, pode-se explanar sobre a Atuação da Controladoria Geral do Município de Curaçá, no Planejamento Público, instrumento que dar direção à gestão, tendo em vista que são objetos orientadores para execução da receita e despesa.

Após estarem desenvolvidas as principais abordagens acerca do tema, no intuito de dar suporte à interpretação dos conceitos levantados, foram coletados dados, através de questionário, contendo 09 (nove) questões que provocam os respondentes a deliberar seu posicionamento, de acordo com a experiência vivida, quando ocupantes do cargo de Controlador Geral no Município de Curaçá.

Das questões levantadas, buscou-se enfatizar informações com vistas à ampliação da análise, alinhando as indagações diretas sobre Controladoria Geral e sua atuação na Administração Pública de Curaçá. Com isso, foi obtido informações de grande relevância para que se pudesse aludir considerações acerca do tema.

Tendo como resultado, os seguintes dados:

Sobre a afirmativa de que o Planejamento Público ocorre anualmente, $100 \%$ dos entrevistados concordaram totalmente (pergunta $\mathbf{n}^{\mathbf{0}} \mathbf{1}$ );

$\checkmark$ Se há a participação da Contabilidade, Controladoria e Secretaria Municipais no Planejamento Público, todos concordaram parcialmente... (pergunta $\mathbf{n}^{\mathbf{0}} 2$ );

$\checkmark$ Todos concordam totalmente que o Planejamento Público é elaborado por etapas, de acordo com os prazos legais(pergunta $\mathbf{n}^{\mathbf{0}} \mathbf{3}$ );

$\checkmark \quad 3$ dos entrevistados concordaram parcialmente e 1 concordou totalmente que a Controladoria participa ativamente do Planejamento Público, sendo o seu papel da essencial ao Planejamento Público, acompanhando todas as etapas do processo (perguntas no 4,5 e 6);

$\checkmark$ Todos, sem exceção, concordaram totalmente que a Controladoria orienta e recomenda adoções medidas para cumprimento do Planejamento Público, de forma precisa e cotidianamente, (perguntas $\mathbf{n}^{\mathbf{0}} \mathbf{7}$ )

$\checkmark$ Por fim, ambos discordaram a sobre a participação da sociedade no Planejamento Público, entendendo ser precário, mas concordaram parcialmente que as necessidades da sociedade são consideradas na elaboração do Planejamento (perguntas $n^{0} 8$ e 9). 


\section{Considerações Finais}

Atualmente, a sociedade clama por uma gestão pública que melhor desempenhe a suas funções, com práticas gerenciais focadas no alcance de objetivos, sendo importante melhorar a confiança da sociedade sobre o modelo de gestão dos recursos colocados aos cuidados das instituições públicas, fazendo-se necessário uma reflexão sobre a importância da ações agregadoras que impliquem em cooperação de todos os setores da Administração Pública, que em conjunto possam alavancar um sistema que tem por objetivo a justa e mais efetiva aplicação dos recursos públicos, respeitando o contribuinte e destinando algo mais em termos de recursos, para o aperfeiçoamento das políticas públicas.

A Controladoria Geral além de ser uma previsão na Constituição Federal e na Lei de Responsabilidade Fiscal gera para os gestores a garantia de acompanhar o desenvolvimento dos serviços públicos, da apropriada aplicação dos recursos e da indispensável preservação do patrimônio público e, ainda, garantindo a transparência das contas públicas, quando implantado de maneira que possibilite cumprir suas funções corretamente se traduzindo em resultados positivos para a administração pública, parceria com o Poder Legislativo deve importante instituir uma lei especifica, respeitando as exigências da Lei de Responsabilidade Fiscal.

Por meio da pesquisa realizada, é possível perceber que as Controladorias ainda precisam de maior atenção por parte dos gestores, tendo em vista a importância que tem para garantir a eficiência na gestão dos recursos públicos. Infelizmente, essa é uma realidade em todo país.

Com a elaboração desse estudo, espera-se que os Município, não só Curaçá, repensem a valorização e adotem medidas para dar suporte a Controladoria Geral, considerando que esse garante que o Planejamento Público reflita de fato a necessidade da sociedade e não meramente, uma vontade política do Administrador.

Sendo de fundamental importância que as ações da Controladoria, sejam aperfeiçoadas de forma contínua e permanente para que se possam atingir a satisfação desejada pela sociedade na qualidade dos serviços oferecidos aos cidadãos, com o objetivo de atingirmos o interesse da coletividade. 


\section{Referências}

ARAÚJO, Inaldo; ARRUDA, Daniel. Contabilidade Pública: Da teoria a prática. São Paulo: Saraiva, 2004.

BORGES, Carlos Alberto Nunes; CAMPOS, Sandra Maria de Carvalho. Implementação, Estudo e Avaliação dos Controles Internos. Belo Horizonte: TCEMG. 1999;

BOTELHO, Milton Mendes. Manual Prático de Controle Interno na Administração Pública Municipal. 2. ed. Curitiba: Juruá. 2008.

Manual Prático de Controle Interno na Administração Pública Municipal.

Curitiba: Juruá. 2005;

CARVAlHO, Deusvaldo. Orçamento e Contabilidade Pública: Teoria, prática e mais de 700 exercícios. 3. ed. Rio de Janeiro: Elsevier, 2007;

CASTRO, Domingos Poubel de. Auditoria e Controle Interno na Administração Pública. Evolução de Controle Interno no Brasil: do Código de Contabilidade de 1922 até a Criação da CGU em 2003. São Paulo: Atlas, 2008;

CONSTITUIÇÃO DA REPÚBLICA FEDERATIVA DO BRASIL. Promulgada em 05 de outubro de 1988;

CRUZ, Flávio da; GLOCK, José Osvaldo. Controle Interno nos Municípios. Orientações para a Implantação com os Tribunais de Contas. 3. ed. São Paulo: Atlas. 2007;

FILHO, José dos Santos Carvalho. Manual de Direito Administrativo. 32. ed. Rio de Janeiro: Lúmen Júris. 2018;

Lei Complementar n..$^{\circ} 101$, de 04 de maio de 2000. Lei $\mathrm{n}^{\circ} 10.028$, de 19 de outubro de 2000. Altera o Decreto-Lei $n^{\circ} 2.848$, de 7 de dezembro de 1940. Código Penal, a Lei ${ }^{\circ} 1.079$, de 10 de abril de 1950, e o Decreto-Lei no 201, de 27 de fevereiro de 1967;

Lei $n^{\circ}$ 4.320, de 17 de março de 1964. Estatui Normas Gerais de Direito Financeiro para elaboração e controle dos orçamentos e balanços da União, dos Estados, dos Municípios e do Distrito Federal. 1964;

MAGAlHÃES, Eliezer Forte Filho. Auditoria Contábil e Financeira em Entidades Governamentais. Fortaleza-Ceará: Gráfica VT. 1996;

MORAES, Antônio Carlos Flores de. Legalidade, Eficiência e Controle da Administração Pública. Belo Horizonte: Fórum. 2007;

MEIRELLES, Hely Lopes. Direito Municipal Brasileiro. 18. ed. São Paulo: Malheiros. 2017; 
PISCITELLI, Roberto B; TIMBÓ, Maria Zulene Farias; ROSA, Maria Berenice. Contabilidade Pública: uma abordagem da administração financeira. São Paulo: Atlas, 2002;

SILVA, Lino Martins da. Contabilidade Governamental: Um enfoque administrativo. 4. ed. São Paulo: Atlas, 2000.

\section{QUESTIONÁRIO}

\section{Parte I - Perfil dos entrevistados}

$1-$ Sexo
a) Feminino
b) Masculino

\section{2 - Grau de instrução}
a) $1^{\circ}$ grau
b) $2^{\circ}$ grau
c) $3^{\circ}$ grau
d) Especialista/Mestre/Doutor

\section{Parte II - Experiência como Controlador no Planejamento Público}

Assinalar de acordo com a legenda a seguir e responder a partir da experiência vivida na gestão exercida:

1 - Discordo totalmente

2 - Discordo

3 - Indiferente

3 - Concordo parcialmente

4 - Concordo totalmente

\begin{tabular}{|c|l|c|c|c|c|c|}
\hline ITEM & \multicolumn{1}{|c|}{ AFIRMATIVAS } & $\mathbf{1}$ & $\mathbf{2}$ & $\mathbf{3}$ & $\mathbf{4}$ & $\mathbf{5}$ \\
\hline 1 & O Planejamento Público ocorre anualmente & & & & & \\
\hline 2 & $\begin{array}{l}\text { Há a participação da Contabilidade, Controladoria e } \\
\text { Secretaria Municipais no Planejamento Público }\end{array}$ & & & & \\
\hline 3 & $\begin{array}{l}\text { O Planejamento Público é elaborado por etapas, de } \\
\text { acordo com os prazos legais }\end{array}$ & & & & \\
\hline 4 & $\begin{array}{l}\text { A Controladoria participa ativamente do Planejamento } \\
\text { Público }\end{array}$ & & & & & \\
\hline 5 & $\begin{array}{l}\text { O papel da Controladoria Geral é essencial no } \\
\text { Planejamento Público }\end{array}$ & & & & \\
\hline 6 & $\begin{array}{l}\text { A Controladoria acompanha tanta a elaboração, quanto } \\
\text { a execução do Planejamento Público }\end{array}$ & & & & \\
\hline
\end{tabular}




\begin{tabular}{|c|l|l|l|l|l|l|} 
& $\begin{array}{l}\text { A Controladoria orienta e recomenda adoções medidas } \\
\text { para cumprimento do Planejamento Público }\end{array}$ & & & & \\
\hline 8 & Há participação da sociedade no Planejamento Público & & & & & \\
\hline 9 & $\begin{array}{l}\text { O Planejamento Público considera as reais necessidade } \\
\text { da sociedade }\end{array}$ & & & & \\
\hline
\end{tabular}

\section{Como citar este artigo (Formato ABNT):}

PAIXÃO, Silvana Rodrigues. Atuação da Controladoria Geral no Planejamento Público Municipal: Análise da Controladoria Geral de Curaçá/BA. Id on Line Rev.Mult. Psic., 2018, vol.12, n.42, p. 399421. ISSN: 1981-1179.

Recebido: 17/09/2018;

Aceito: 25/09/2018 